\title{
Overview of Physical Therapy for Children with Cerebral Palsy
}

\author{
Tae-Young Oh \\ Dept. of Physical Therapy, Health and Welfare College, Silla University
}

\begin{abstract}
Purpose This study was to find out proper concept and intervention to treat in physical therapist' s perspective according to recognize the changing definition of cerebral palsy, and to investigate the several classification and intervention for children with cerebral palsy. Methods The electronic journal site was searched by terms "cerebral palsy", "intervention", physical therapy". We analyzed and descript the total 24 cited articles from 9 articles in Science Direct, and 16 articles in K-RISS from 20 Oct. 2018 to 7 Jan. 2019. Results Later definition of cerebral palsy emphasized secondary musculoskeletal problem over time in children with cerebral palsy. In early definition emphasized person's function or neurological disability. Prevalence rate of cerebral palsy were $6 \sim 8 \%$ from perinatal asphyxia, the overall prevalence of cerebral palsy has remained constant in recent years despite increased survival of at-risk preterm infants. Gross Motor Function Classification System (GMFCS) has been widely employed internationally to group individuals with cerebral palsy into one of five levels based on functional mobility or activity limitation. The treatment must be goal oriented, such as to assist with mobility, reduce or prevent contractures, improve positioning and hygiene, and provided comfort. Each member of the child's multidisciplinary team, including the child and both parents, should participate in the serial evaluation and treatment planning. Conclusion We found that the definition of cerebral palsy is changing to focus on secondary problem over time and the children with cerebral palsy is best cared for with an individualized treatment plan that provides a combination of interventions.
\end{abstract}

Keyword Cerebral Palsy, Definition, Classification, Intervention, Physical Therapy,

Corresponding author Tae-Young Oh(ohtaeyoung@silla.ac.kr)

$\begin{array}{lll}\text { Received date } & 21 \text { January } 2019 \\ \text { Revised date } & 31 \text { January } 2019 \\ \text { Accepted date } & 07 \text { February } 2019\end{array}$

\section{Introduction}

Cerebral palsy was described in 1862 by an orthopedic surgeon, William James Little first, a motor disorder resulting from a non-progressive insult to the developing brain. ${ }^{1)}$ Children with cerebral palsy suffer from multiple problems and potential disabilities such as mental retardation, epilepsy, feeding difficulties, and ophthalmologic and hearing impairment.

Dzienkowski et al (1996) recommended the primary health care practitioner must be prepared to recognize neuro-motor deficits, diagnose and classify the type of disorder, and implement a methodical treatment plan. Early institution of physical, occupational, and speech therapies are essential for proper developmental progress. ${ }^{2}$

http:dx.doi.org/10.17817/2019.01.31.111372
Physical therapy plays a central role in managing the children with cerebral palsy and it focuses on function, active movement, and optimal use of the child's potential. ${ }^{3)}$ Physical therapy uses physical approaches to promote, maintain, and restore physical, psychological, and social well-being. $\left.{ }^{4}\right)$

The best care for the children with cerebral palsy is an individualized treatment plan that can provide a combination of intervention. ${ }^{5)}$ Therapeutic intervention included formulating an individualized treatment plan that is functional, goal-oriented, time-limited, and cost-effective. This treatment plan should be team delivered and hospital-home-rehabilitation center-based according to the needs of each child. ${ }^{6}$

In the last decade, the evidence based treatment of cerebral palsy has rapidly expanded, providing clinicians and families with the possibility of newer, safe, and more effective interventions. ${ }^{7)}$ Sakzewski et al 
(2009) found that Orthopaedic surgery and movement normalization were once the mainstays of intervention, but localized anti-spasticity medications and motor learning intervention have gained increased popularity.

The intervention for children with cerebral palsy strongly require the provision of a number of family-centered services that make a difference in the lives of these children and their families. ${ }^{5)}$ Setting realistic goals, determination of the priorities, informing the family and enhancing family participation in physical therapy programs will increase the success of physical therapy. ${ }^{8)}$

The purpose of this study is to find out proper concept and intervention to treat children with cerebral palsy in physical therapist's perspective according to recognize the changing definition of cerebral palsy, and to investigate the several classification and intervention for children with cerebral palsy.

\section{Method}

The electronic journal site was searched by the search terms "cerebral palsy", "intervention", we analyzed and descript the total 24 cited articles from 9 articles in Science Direct, and 16 articles in K- RISS.

\section{Results}

\section{The change of definition of cerebral palsy.}

In 1964 cerebral palsy is defined as that a disorder of movement and posture due to a defect or lesion of the immature brain. And the disorder of cerebral palsy was mainly focused on posture and movement. ${ }^{9)} \mathrm{A}$ clinical presentation of wide variety of cerebral cortical or sub cortical insults occurring during the first year of life.

Rosenbaum et al (2000) defined the cerebral palsy that a group of permanent disorder of the development of movement and posture causing activity limitation, that are attributed to non-progressive disturbance that occurred in the developing fetal or in- fant brain.

Rosenbaum et al (2007) modified the definition of cerebral palsy as that the motor disorders of cerebral palsy are often accompanied by disturbance of sensation, cognition, communication, perception, behavior, by a epilepsy and by secondary musculoskeletal problems.

Later definition of cerebral palsy emphasized secondary musculoskeletal problem over time in children with cerebral palsy. In early definition emphasized person's function or neurological disability.

\section{Etiology and prevalence of cerebral palsy}

Originally cerebral palsy was largely attributed to acute hypoxia during labor or birth, but now evidence indicates that most lesions occur in the second half of gestation, an active period of brain development. ${ }^{10)}$

Current evidence suggests that a multiplicity of risk factors contribute to cerebral palsy rather than a single event. Single events such as uterine rupture, cord prolapse, major placental abruption resulting in hypoxic insults to the brain account for a small proportion. Birth asphyxia is not a common antecedent. $^{11)}$

According Jan (2006) describe, preterm infants are at the highest risk for developing cerebral palsy. The vulnerable brain is harmed during a critical period of development primarily by known CNS complications of prematurity such as intraventricular hemorrhage and periventricular leukomalacia.

Children with cerebral palsy prevalence increases with lower birthweight and higher immaturity. Increase of survival after preterm birth has first also increased cerebral palsy rates. In the 1980s, this trend was reversed for lower birth weight infants, and in the 1990s, for very lower birth weight or very immature infants. ${ }^{12)}$

The study from 2006 to 2007 by $\mathrm{Oh}(2007)$ in Korea presented that the cause of cerebral palsy in thought to be multifactorial including prematurity, inflammation, genetic cause and environmental factor. Although evidence suggested that $70 \sim 80 \%$ of cerebral palsy is due to prenatal factors and birth asphyxia palsy a relatively minor role. 
Table 1. Classification of Cerebral Palsy

\begin{tabular}{|c|c|c|c|}
\hline AACP (Minear, 1956) & Bobath (1997) & AACPDM (1997) & SCPE (2008) \\
\hline Spastic & Spastic & Spastic & Spastic \\
\hline Athetosis & Severe & Dyskinetic & Dyskinetic \\
\hline tension & moderate & Hypotonic & dystonic \\
\hline non tension & Athetosis & Ataxic & choreoathetosis \\
\hline dystonic & with spasticity & Mixed & nonclassibiable \\
\hline tremor & with tonic spasm & & Ataxic \\
\hline Rigidity & with intermittent spasm & & Non classifiable \\
\hline Ataxia & choreoathetosis & & \\
\hline Tremor & Ataxia & & \\
\hline Atonic & Hypotonia & & \\
\hline \multicolumn{4}{|l|}{ Mixed } \\
\hline Unclassified & & & \\
\hline
\end{tabular}

AACP : American Academy of Cerebral Palsy

AACPDM : American Academy of Cerebral Palsy and Developmental Medicine

SCPE : Surveillance of Cerebral Palsy in Europe.

In the study of Korea, Cheon (2014) presented that the risk factor for major neurodevelopmental impairments in very lower birth weight infants was related on preterm birth and minimizing hypotension shock and severe IVH.

Prevalence rate of cerebral palsy were $6 \sim 8 \%$ from perinatal asphyxia, ${ }^{13)}$ the overall prevalence of cerebral palsy has remained constant in recent years despite increased survival of at-risk preterm infants. ${ }^{14)}$

\section{Classification of cerebral palsy}

(1) Classification by neurological condition (Table 1)

The neurological condition could be assessed by tone abnormality, as well as the diagnosed movement disorder present such as spasticity, ataxia, dystonia, athetosis. The type of abnormal muscle tone or involuntary movement disorder observed or elicited is usually assumed to be related to the underlying pathophysiology of the disorder, and may also reflect etiologic circumstance. ${ }^{15)}$

The SCPE (Surveillance of Cerebral Palsy in Europe) classified cerebral palsy into two subtype between spastic and dyskinetic type. This classification of subtype requires an assessment of the predominant motor disorder. It proposed that children continue to be classified by the predominant type of tone or movement abnormality, but any additional tone or movement abnormalities present should be listed as secondary type.

(2) Classification by topographic of motor involvement. Cerebral palsy can be classified according to the topographic distribution of motor involvement. Motor deficits include monoplegia, diplegia, hemiplegia, triplegia, quadriplegia and double hemiplegia." Monoplegia involved one limb, hemiplegia that lateralized one-half of the body is affected. Triplegia involved 3 extremities, usually both legs and one arm. They may represent hemiplegia plus paraplegia or incomplete quadriplegia. Quadriplegia or Tetraplegia involved all 4 extremities. Diplegia is paralysis affecting like parts on either side of the body in bilateral paralysis. Double hemiplegia also is seldom term and implies those cases in which the arms are more involved than the legs. ${ }^{16)}$

According SCPE guideline, any additional tone or movement abnormalities present should be listed as secondary types, as well as the anatomical distribution or topographic of feature like as bilateral, unilateral. The SCPE classification of subtype proposed that spastic bilateral, spastic unilateral, dyskinetic dystonic, dyskinetic choreoathetotic, dyskinetic non-classifiable., ataxic, non classifiable.

(3) Classification by functional level

The functional consequences of involvement of the 
upper and lower extremities should there for be separately classified using objective functional scales. Gross Motor Function Classification System (GMFCS) has been widely employed internationally to group individuals with cerebral palsy into one of five levels based on functional mobility or activity limitation. ${ }^{17}$

The GMFCS was developed for children with cerebral palsy who are 12 years of age and younger and subsequently expanded to include a 12 to 18 year age band revised to include environmental and personal considerations for the 6 to 12 year and 12 to 18 year bands(Table 2). ${ }^{18)}$

The GMFCS is a 5 level classification system that describes the gross motor function of children and youth with cerebral palsy on the basis of their self-initiated movement with particular emphasis on sitting, walking, and wheeled mobility. The GMFCS measures what children do in their typical settings (performance), not what they are able to do in an ideal environment (capability). The GMFCS is one of the most widely used classification systems for individuals with cerebral palsy, as it is used in clinical examinations, research, and population based studies. ${ }^{19)}$

The Manual Ability Classification System (MACS) has been developed to classify how children with cerebral palsy use their hands when handling objects in daily activities. The classification is designed to reflect the child's typical manual performance, not the child's maximal capacity. It classifieds the collaborative use of hands together. ${ }^{20)}$ The MACS is a five level system to classify hand use of children with cerebral palsy 4 to 18 years of age. Classification is based on the child's typical performance in handling objects during daily activities. Distinctions among the levels are based on the child's ability to handle objects and the amount of assistance or adaptation the child needs to complete tasks of daily living. ${ }^{20)}$

\section{Intervention for cerebral palsy (1) Medical management}

Botulinum toxin A injections are being used more frequently to treat upper and lower extremity spasticity and hypertonia in children with cerebral palsy.

Management of spasticity is a major challenge to the rehabilitation team. The initial management has centered on the elimination of externally exacerbating causes, physical therapy, splinting and casting. Medical management has centered on anti-spasticity medication use, but more recently focal treatment

\section{Table 2. GMFCS between 12 and 18 birthday : Descriptors(Palisano et al, 2008)}

\section{Level}

GMFCS Level 1

GMFCS Level 2 Youth walk in most settings but environmental factors and personal choice influence mobility choices. At school or work they may require a hand held mobility device for safety and climb stairs holding onto a railing. Outdoors and in the community youth may use wheeled mobility when traveling long distances.

GMFCS Level 3 Youth are capable of walking using a hand held mobility device. Youth may climb stairs holding onto a railing with supervision or assistance. At school they may self-propel a manual wheelchair or use powered mobility. Outdoors and in the community youth are transported in a wheelchair or use powered mobility

GMFCS Level 4 Youth use wheeled mobility in most settings. Physical assistance of 1-2 people is required for transfers. Indoors, youth may walk short distances with physical assistance, use wheeled mobility or a body support walker when positioned. They may operate a powered chair, otherwise are transported in a manual wheelchair.

GMFCS Level 5 Youth are transported in a manual wheelchair in all settings. Youth are limited in their ability to maintain antigravity head and trunk postures and control leg and arm movements. Self-mobility is severely limited, even with the use of assistive technology 
methods including phenol blocks and botulinum toxin have been utilized. There has been an increased use of intrathecal baclofen in the management of refractory tone. Dorsal rhizotomy has been advocated for a selective population of children with spasticity. There is no standardized approach to spasticity management and this paper will discuss the importance of evidence-based treatment of spasticity that is adapted for the individual child. ${ }^{21)}$

Botulinum toxin type A(BTX), a neuromuscular blocking agent, reduced muscle tone in various neuromuscular disorders. The safety and short term efficacy of BTX injections were evaluated in a prospective, 3 months, double blind, randomized clinical trial involving 114 children with cerebral palsy and dynamic equinus foot deformity. Outcome was determined by observational gait analysis, ankle range of motion measurements and quantification of muscle denervation by nerve conduction. Patients in the BTX group demonstrated improved gait function and partial denervation of the injected muscle. ${ }^{22)}$

Three drugs diazepam, dantrolene and baclofen have been commonly used to alleviate spasticity in cerebral palsy; and debate remains about their usefulness and there is a Cochrane protocol to assess the absolute, and comparative, efficacy of baclofen, dantrolene and diazepam for spasticity in cerebral palsy. Intrathecal baclofen, a much more invasive treatment has been recently introduced and a separate Cochrane protocol will review the evidence for the effectiveness of intrathecal baclofen. ${ }^{23), 24)}$

A surgical method to reduce spasticity by selective posterior nerve root division was first described in 1913 and reintroduced in the 1970s. Numerous studies with confounding, selection bias, lack of controls and use of variable surgical techniques, and application of subjective outcome measures have reported good results leading to the widespread use of this technique. The absence of good evidence to support its efficacy and the lack of information about safety and long term consequences has led to some controversy and the role of this technique, which is expensive and very demanding of the child, family, surgeon and therapist, needs to be justified. There is a Cochrane protocol designed to determine the effectiveness of selective dorsal rhizotomy in the management of children with spastic cerebral palsy. ${ }^{23), 25)}$

\section{(2) Physical therapy for children with cerebral palsy}

An 8 month, standardized, functionally based on exercise program significantly improved physical fitness, the intensity of activities and Health Related Quality of Life (HRQOL) in children with cerebral palsy when added to standard care. From an evaluation of the available data it appears that children and adolescents with cerebral palsy may benefit from exercise programs that focus on lower extremity muscle strength and/or cardiovascular fitness. ${ }^{26}$

Han et al(2018) presents that cranio-cervical flexion based trunk stabilization exercise for 20 minutes a day, 2 times per week total 8 weeks increased significant on Modified Ashworth Scale (MAS), Pediatric Reach Test (PRT) and Trunk Control Measurement Scale (TCMS). ${ }^{27)}$ The cranio-cervical flexion exercise included chin pull, flexion of head and neck, abdominal throwing exercise, bridging exercise.

In 2012, Choi et al(2012) study showed that trunk muscle strengthening exercise for 3 times per week, total 6 weeks were effective in improving the balance performance of sitting posture for the children with spastic diplegic cerebral palsy without changing muscle tone. ${ }^{28)}$ The trunk muscle strengthening exercise consisted of 2 exercises to strengthen abdominal muscles and back muscles.

Muscle strengthening exercise with Thera band were effective on balance and gait for children with cerebral palsy. This single subject designed(3 participations) study presented that muscle strengthening exercise for 3 times per week total 8 week improved subjects gross motor function, balance ability, gait ability.

\section{(3) Neurodevelopmental intervention}

Webb(2008) presented that there was a lack of evidence to support the efficacy of any particular physical therapy and that it was difficult to establish the advantages of one particular therapeutic method over another. $^{23)}$ 
Palmer et al(1988) suggested that he group that received program of infant stimulation followed by NDT progressed more quickly (measured using the Griffiths Development Test) than the group who received NDT alone. There was no significant differences between the group in the incidence of contractures, or the need for orthopaedic intervention. The result emphasizes the importance of measuring outcomes other than locomotion and inputs from local services. ${ }^{29)}$

Law et al(1997) found no benefit of intensive NDT, ${ }^{30)}$ but Bower et al(2001) found that there was a nonsignificant trend for benefit for the intensive group when additional covariates of age and severity were introduced, not in the primary analysis and the effect was short lived. ${ }^{31}$

\section{(4) Alternative intervention}

Acupuncture has been used to treat children and adolescents with CP for more than 20 years. Benefits claimed for acupuncture have included warmer extremities, a decrease in painful spasms, improvement in the use of arms or legs, more restful sleep, improvement in mood and better bowel function. ${ }^{23)}$

Lu et al(2017) presents the study which the effect of scalp acupuncture on the treatment of children with cerebral palsy in America. ${ }^{32)}$ Thirty-six children with cerebral palsy were treated with Chinese scalp acupuncture on motor and sensory are, motor area, speech 1, 2 area, balance area, vision area, apraxia area, 1 vision area. These children received between 3 20 treatment, 5 children complete resolution of their symptom, 14 cases a marked effect, 14 had some effect, 3 patients experienced no improvement.

According to Kang \& Song(2010), the horseback riding simulation machine training for 15 minutes a day, 3 times per week, total 12 weeks showed significant increasing in all dimensions of GMFM. They recommended that the horseback riding simulating training should be considered as therapeutic method for physical therapy for the children with cerebral palsy to improve the functional movement.

Romeo et al(2018) suggested that Lycra suit are effective on improving for motor function and static balance in children with cerebral palsy. ${ }^{33)}$ The five chil- dren with cerebral palsy wore the Lycra suit for more than 4 hour per day for 6 months. An immediate improvement of static balance was observed at baseline, with the first use of the Lycra suit. Further improvement was observed at the 6 month follow up, with a statistical significant for the parameters assessing the antero-posterior axis.

\section{Intervention for in the future}

Jan (2006) presented that the treatment must be goal oriented, such as to assist with mobility, reduce or prevent contractures, improve positioning and hygiene, and provided comfort. Each member of the child's multidisciplinary team, including the child and both parents, should participate in the serial evaluation and treatment planning. ${ }^{5)}$

According Lowing et al (2009), the definition of goal directed therapy was a therapy that emphasizes the learning of meaningful activities (expressed as goals) in the child's environment, wherein the activities are regarded as important by the child, the parents and others in the child's environment. ${ }^{34)}$ The goals are established based on the parents' and children's priorities. Learning takes place in individually-tailored interventions in the child's natural environment by repetitive practice of the everyday goal activities, in a motivated, challenging and playful way, and in combination with impairment-focused interventions. The overall aim of the therapy is to improve everyday performance in activities and participation. In goal directed therapy, emphasis is directed towards the child and family in the goal-setting process with the aim to select goals that are meaningful in the lives of the child and family.

King et al (2004) emphasized that family centered service is both a philosophy and an approach to service delivery that is considered to be a best practice in early intervention and pediatric rehabilitation. ${ }^{35)}$ And definition of family is that is made up of a set of values, attitudes, and approaches to services for children with special needs and their families. Family-centered service recognizes that each family is unique; that the family is the constant in the child's life; and that they are the experts on the child's abilities and needs. The 
Family works together with service providers to make informed decisions about the services and supports the child and family received. In family-centered service, the strengths and needs of all family members are considered.

\section{Conclusion}

The definition of cerebral palsy is changing to focus on secondary problem over time from neurological condition and original impairment. Prevalence rate of cerebral palsy were $6 \sim 8 \%$ from perinatal asphyxia, ${ }^{13)}$ the overall prevalence of cerebral palsy has remained constant in recent years despite increased survival of at-risk preterm infants

The traditional classification by motor impairment or tone distribution will be less the impact than activities and participation in daily living activities.

The child with cerebral palsy is best cared for with an individualized treatment plan that provides a combination of interventions. This requires the provision of a number of family-centered services that make a difference in the lives of these children and their families

\section{References}

1. Shevell MI, Bodensteiner JB. Cerebral palsy: defining the problem. Semin Pediatr Neurol. 2004;11(1):2-4

2. Nygraad TG, Marsden CD, Fahn S. Dopa. responsive dystonia: long-term treatment response and prognosis. Neurology. 1991;41:174-81.

3. Caspersen CJ, Powell KE, Christenson GM. Physical activity, exercise, and physical fitness: definitions and distinctions for health-related research. Public Health Rep. 1985;100:126-31.

4. Bobath B. Bobath course notes(8-week paediatric course). London. The Bobath Centre. 1997

5. Jan MM. Cerebral palsy: Comprehensive review and update. Ann Saudi Med 26,2(2006):123-32.

6. Horn E. Achieving meaningful motor skills: conceptual and empirical based of a neurobehavioral. Ment Retard Dev Disabil. 1997;3: 138-44.

7. Novak I, Mcintyre S, Morgan C et al. A systematic review of interventions for children with cerebral palsy: state of the evidence. Dev Med Child Neurol. 2013;55(10):885-910.

8. Gunel MK. Rehabilitation of children with cerebral palsy from a physiotherapist's perspective. Acta Orthop Traumatol Turc. 2009;43(2):173-80.

9. Bax, Martin CO. "Terminology and classification of cerebral palsy." Developmental Medicine \& Child Neurology .1964;6(3): 295-7.

10. Hadders-Algra M. The neuronal group selection theory: promising principle for understanding and treating developmental motor disorders. Dev Med Child Neurol. 2000;42:707-15

11. Nelson KB. Causative factors in cerebral palsy. Clin Obstet Gymecol. 2008;51:129-135..

12. Krägeloh-Mann I \& Christine C. Cerebral palsy update. Brain and development . 2009;31(7): 537-44.

13. Blair E \& Stanley F. Intrpartum asphyxia: a rare cause of cerebral palsy. The Journal of pediatrics. 1988;112(41):515-9.

14. Oskoui M, Coutinho F, Dykeman J et al. An update on the prevalence of cerebral palsy: a systematic review and meta-analysis. Dev Med Child Neurol. 2013;55(6):509-19

15. Rosenbaum P, Paneth N, Leviton A et al. A report: the definition and classification of cerebral palsy. Aril 2006. Dev Med Child Neurol. 200749(6): 8-14.

16. Minear WL, Binkley E, Snow WB. Report, Nomenclature and classification committee, presented before American Academy for Cerebral Palsy. November, 1954.

17. Beckung E, Hagberg G. Neuro impairments, activity limitations, and participation restrictions in children with cerebral palsy. Dev Med Child Neurol. 2002;44:309-16.

18. Palisano RJ, Rosenbaum P, Bartlett D et al. Content validity of the expanded and revised gross motor function classification system. Dev Med Child Neurol. 2008;55(10): 744-50.

19. Palisano RJ, Rosenbaum P, Bartlett D et al. Canchild center for childhood disability research. McMaster University. 2007.

20. Eliasson AC, Krumlinde-Sundholm L, Rosblad B et al. The manual ability classification system(MACS) for children with cerebral palsy: scale development and evidence of validity and reliability. Dev Med Child Neurol. 2006;47(7): 549-54.

21. Koman L A, Mooney JF, Smith BP et al. Botulinum 
toxin type A neuromuscular blockade in the treatment of lower extremity spasticity in cerebral palsy: a randomized, double blind, placebo controlled trial. Journal of Pediatric Orthopaedics. 2000;20(1): 108.

22. Webb M. A rapid review of the evidence for the effectiveness of Bobath therapy for children and adolescents with cerebral palsy. National Public Health Service for Wales. Local Health Board Public Health, Medical and Nurse Directors. 2008.

23. Howard DC. Anti spastic medication for spasticity in cerebral palsy. Cochrane database of systematic reviews 2000. DOI: 10.1002/14651858.CD002260.

24. Narayanan U \& Howard A. Selective dorsal rhizotomy in the management of children with cerebral palsy. Cochrane database of systematic reviews. 2004. DOI:10.1002/14651858.CD003360.

25. Verschuren O. Ketelaar M; Gorter JW et al. Exercise training program in children and adolescents with cerebral palsy: a randomized controlled trial. Arch Pediatr Adolesc Med. 2007;16(1): 1075-81.

26. Han SJ, Lee BH, Chung EJ. The effects of cranio-cervical flexion based trunk stabilization exercise on muscle tone and sitting balance in children with spastic cerebral palsy. Journal of special Education \& Rehabilitation Science. 2018;57(3): 413-32.

27. Choi YC, Lee JH, Kim JS. The effects of trunk muscle strengthening exercises on balance performance of sitting posture and muscle tone of children with cerebral palsy. Journal of the Korea Academya-Industrial cooperation Society. 2012;13(9): 4098-106.

28. Palmer FB, Shapiro BK, Wachtel RC et al. The effects of physical therapy on cerebral palsy on cerebral palsy: a controlled trial in infants with spastic diplegia. N Engl J Med. 1988;318:803-8.

29. Law M, Russell D, Pollock N et al. A comparison of intensive neurodevelopmental therapy plus casting and a regular occupational therapy program for children with cerebral palsy. Dev Med Child Neurol. 1997;39: 664-70.

30. Bower E; Mitchell D; Burnett $\mathrm{M}$ et al. Randomized controlled trial of physiotherapy in 56 children with cerebral palsy followed for 18 months. Dev Med Child Neurol. 2001;43: 4-15.
31. Lu XL, Hao JS, Sun ZR et al. Treatment of cerebral palsy with Chinese scalp acupuncture. World Journal of Acupuncture Moxibustion. 2017;27(2): 62-73.

32. Romeo DM, Specchia A, Sini F et al. Effects of Lycra suits in children with cerebral palsy. European Journal of Paediatric Neurology. 2018;22:831-6.

33. Lowing K, Bexelius A, Brogren CE. Activity focused and goal directed therapy for children with cerebral palsy. Do goal make a difference? Disabil Rehabil. 2009;31(22):1808-166.

34. King S, Teplicky R, King G et al. Family-centered service for children with cerebral palsy and their families: a review of the literature. In: Seminars in pediatric neurology. WB Saunders. 2004.

35. Bobath K. The normal postural reflex mechanism and its deviation in children with cerebral palsy. Physiotherap. 1971;57:515-25.

36. Cheon MK, Yum SK, Moon CJ et al. Risk factors for severity of intraventricular hemorrhage in very low birth weight infants and neurodevelopmental outcome. Korean J Perinatol. 2014;25(4): 266-75

37. Dzienkowski RC, Smith KK, Dillow KA et al. Cerebral palsy: a comprehensive review. The Nurse practitioner. 1996;21(2):45-8.

38. Gainsborough M, Surman G, Maestri G et al. Validity and reliability of the guidelines of the surveillance of cerebral palsy in Europe for the classification of cerebral palsy. Dev Med Child Neurol. 2008;50: 828-31.

39. Matthews Balaban B. Management of spasticity in children with cerebral palsy. Acta Ortop Traumatol Turc. 2009;43(2):81-6.

40. Minear WL. A classification of cerebral palsy. Pediatrics. 1956;18(5): 841-52.

41. Oh SY. Current opinion of cerebral palsy. Korean Journal of Obstetrics and Gynectology. 2007;50(9):1191-204.

42. Sakzewski L, Ziviani J, Boyd R. Systematic review and meta-analysis of therapeutic management of upper-limb dysfunction in children with congenital hemiplegia. Pediatrics. 2009;123: e1111-22. 


\title{
The Effects of Whole-body Vibration on the Gross Motor Function, Balance, and Gait of Children with Cerebral Palsy
}

\author{
Dong-Baek Son ${ }^{1}$, Kyoung-Bo Lee ${ }^{1}$, Byong-Yong, Hwang ${ }^{* 2}$ \\ 'Dept. of Physical Therapy, St. Vincent Hospital \\ ${ }^{*}$ Dept. of Physical Therapy, College of Health \& Welfare, Yong-In University
}

\begin{abstract}
Purpose The aim of this study was to determine the effect of Whole-Body Vibration on gross motor function and balance, gait of children with cerebral palsy. Methods The Design is ABA design of single-subject experimental design. This study participate 2 subjects for 7 years old who were diagnosed children with spastic cerebral palsy. Baseline(A) and Baseline(A') phases were received not WBV, Intervention(B) phase provided with 30 minutes WBV in 10 session. All subjects were measured with the Gross Motor Function Measure(GMFM-66), Pediatric Balance Scale(PBS), One leg standing, Gait analysis in session and at follow-up. Results The results showed that the subjects increased GMFM-66 score and remained in the assessment after the intervention. But the subject 2 was decrease again after baseline(A'). PBS of both subjects increased until after intervention but decreased during baseline(A'). In the one leg standing, both subjects increased after the baseline(A). Especially, the sessions exceeding the two standard deviation in the intervention process were 5 times and 8 times, respectively. The gait symmetry index of both subjects increased after intervention. Conclusion WBV was effective in improving gross motor and balance, gait in children with cerebral palsy.
\end{abstract}

Key words Whole-Body Vibration, Cerebral Palsy, Gross Motor Function, Balance, Gait

Corresponding author Byong-Yong Hwang (bobathkorea@naver.com)
Received date
21 January 2019
Revised date
31 January 2019
Accepted date
12 February 2019

\section{Introduction}

Cerebral palsy is a non-progressive disease accompanied by difficulties in movement and postural control. ${ }^{1)}$ Activity is compromised by poor movement and postural development, as well as problems with sensation, perception, behavior, and secondary musculoskeletal development. ${ }^{2)}$ Cerebral palsy is one of the most common causes of physical impairment in childhood. ${ }^{3)}$ Such children exhibit higher-level sensory impairments and muscle tension than do their peers. They find it difficult to control their muscles, compromising the ability to exercise. ${ }^{4)}$ Several researchers have found that muscle strength in such children is related to motor function. 5),6),7) Various physical therapies improve latent motor ability and ameliorate the secondary problems. ${ }^{8)}$ The interventions include task-oriented exercises, ${ }^{9}$ progressive resistance ex-

http:dx.doi.org/10.17817/2019.01.31.111370 ercises ${ }^{10)}$ virtual reality training, ${ }^{11)}$ treadmill work, weight-training machines (tilting tables), ${ }^{12)}$ and whole-body vibration (WBV). ${ }^{3), 13), 14), 15)}$ Saquetto et al. (2015) found that WBV was associated with functional improvements in children with cerebral palsy, enhancing flexibility, posture control, balance, and coordination. ${ }^{16)}$ WBV is a form of neuromuscular training that uses vibration to stimulate points critical in terms of balance maintenance (thus, points exhibiting vibration reflexes; abbreviated TVRs). ${ }^{17)}$ When vibrations of a floor are transmitted throughout the body, these vibrations stimulate both the spine and the appendages, transmitting contraction commands to the spinal cord, enhancing muscle response rates and aiding movement by activating the nervous system. In addition, many exercises seek to mobilize (excite) the Golgi tendon organ. ${ }^{18)}$ Although many studies have explored the effects of whole-body vibration on subjects with various conditions, few works on children with cerebral palsy have appeared; it is difficult to de- 
Table 1. General characteristics of the subjects

\begin{tabular}{ccccccc} 
Subject & Gender & $\begin{array}{c}\text { Age } \\
\text { (years) }\end{array}$ & $\begin{array}{c}\text { Weight } \\
(\mathrm{kg})\end{array}$ & $\begin{array}{c}\text { Height } \\
\text { (cm) }\end{array}$ & $\begin{array}{c}\text { GMFCS } \\
\text { Diagnosis }\end{array}$ \\
\hline 1 & Male & 7 & 33 & 127 & Rt. hemipleia & 1 \\
2 & Male & 7 & 27 & 122 & Diplegia & 1 \\
\hline
\end{tabular}

termine if the initial effects persist. Here, we suggest that whole-body vibration benefits children with cerebral palsy. We sought to improve function using an appropriate intervention.

\section{Materials and Methods}

\section{Subjects}

We studied two children diagnosed with cerebral palsy in S hospital of Suwon City, Gyeonggi-do, South Korea; both were undergoing rehabilitation. Their parents gave written informed consent. The general characteristics of the subjects are in Table 1 . The study period ran from March 5, 2018 to May 30, 2018, thus for about 3 months.

\section{Methods}

(1) Procedure and intervention

We used the single-subject, ABA research design. Baseline (phase A) and later phase (phase A') data were each collected 5 times in the absence of vibration; interventional (phase B) data were collected 10 times. The whole-body vibrator was a Galileo Med-S model (Novotec Medical GmbH, Pforzheim, Germany) delivering alternating sinusoidal oscillations at $1-27 \mathrm{~Hz}$ at an amplitude of $0 \pm 3.9 \mathrm{~mm}$. Both subjects bent their knees by about $30^{\circ}$ when on the footboard and bent their hips and ankles slightly with the feet about $20 \mathrm{~cm}$ apart. Vibration was applied in blocks of 6 min (two 3-min sessions with a rest of 1-2 min between sessions; five sequences in total over 30 min). Over the sessions, the vibrational frequency was gradually increased by $0.5 \mathrm{~Hz}$ (within the range 11-18 $\mathrm{Hz}$ ) as tolerated by the children, who wore waist belts to protect against falls. If a child complained of fatigue or dizziness, exercise was immediately paused for $1-2 \mathrm{~min}$.

\section{Measurements}

(1) Gross Motor Function

We used a Gross Motor Function Measure (the GMFM-66) appropriate for children with cerebral palsy aged 0-18 years. The five assessment panels feature 66 items, thus fewer than the GMFM-88; scores can be obtained without evaluating all items. In addition, responses are ranked in terms of difficulty; functional ability is readily assessed. ${ }^{19)}$ The scores for each item ranged from 0 (failure) to 3 (complete success); the test-retest reliability was $0.99 .^{20)}$ In other studies, the test-retest reliability was 0.97 and the interlaboratory reliability $0.98 .^{21)}$ All scores were estimated using Gross Motor Ability Estimator (GMAE) software and were calculated at baseline, before, and twice after intervention (four assessments in all).

\section{(2) Balance}

The Pediatric Balance Scale (PBS) was used to analyze changes in balance. The 14 items of the revised Berg Balance Scale include the time taken to maintain

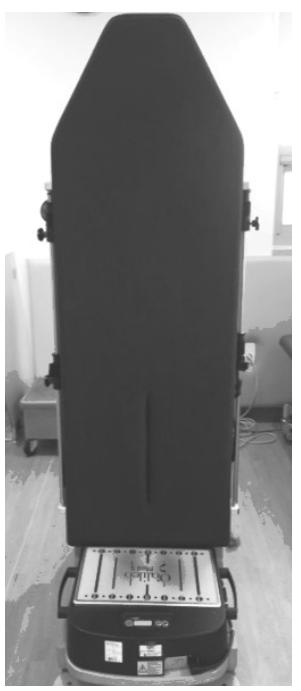

Figure 1. Galileo Med S 
a sitting posture, the quality of the posture per se, and the ability to maintain head posture for $30 \mathrm{~s}$ (less than the time of the original Scale). Each test was attempted up to three times; the scores ranged from 0 to 4 and four assessments were conducted (as described above). The attributes required to stably perform independent activities at school, at home, and in the community include competence in terms of balance when sitting, writing, stretching, turning, and climbing stairs. The intra-rater and inter-rater correlation coefficients attained $0.99 .^{22}$ Also, the maximum duration of one-leg standing on the more affected side was measured ${ }^{23)}$; this is an important measure of postural control. ${ }^{24)}$

\section{(3) Gait}

A G-sensor (BTS Bioengineering S.p.A., Milan, Italy) was used to measure walking/gait parameters and shaking. Walking cadence, average speed, walking period, and the walking and standing positions were measured by reference to changes in the center-of-gravity (at the L4-5 level) accelerations on the $\mathrm{x}-, \quad \mathrm{y}-$, and $\mathrm{z}$-axes, using an accelerometer and a gyroscope. All data were analyzed using G-studio software. ${ }^{25)}$ We also evaluated walking symmetry by representing leg accelerations during gait as curves ${ }^{26}$; we compared the two curves using the following formula.

Symmetric Index $=\{(\operatorname{corr} \dagger+1) \times 100\} / 2$

$\dagger$ corr : cross correlation coefficient of the parameter

Complete overlap of the two curves corresponds to a score of 100. The children walked back and forth for $8 \mathrm{~m}$ at a natural speed ${ }^{27)}$; four assessments were performed (as described above).

\section{Statistics analysis}

The baseline and test data are presented as graphs

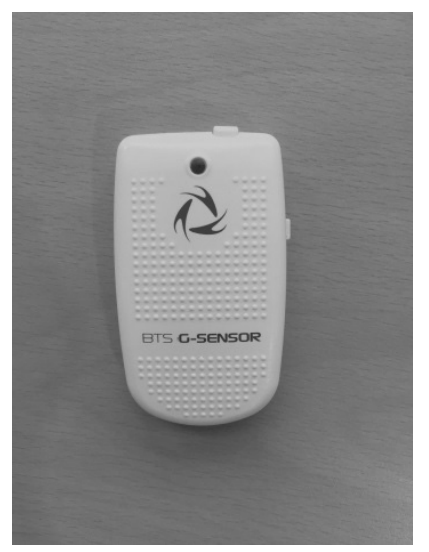

Figure 2. G-SENSOR

with descriptive statistics; averages (with two standard deviations) were compared between the baseline and test periods. Our analyses of changes afforded by intervention were thus sensitive. ${ }^{28)}$ Any data that lay outside the mean \pm two standard deviations was considered significant. ${ }^{29)}$

\section{Results}

\section{Gross Motor Function}

The major outcomes are listed in Table 2. The initial baseline score of subject 1 was $82.99 \%$, and this was maintained at the pre-test assessment. After 10 whole-body vibration exercises, the score improved to $86.52 \%$ and was maintained after the post-test. The initial baseline score of subject 2 was $77.46 \%$ and was maintained at the pre-test. After intervention, the score increased to $78.82 \%$, but decreased after the post-test.

\section{Balance}

The baseline PBS score of subject 1 was 47 and was maintained on the pre-test assessment. After 10 interventions, the score improved to 53 , but fell to 50 after post-test. The baseline PBS score of subject 2 was 47 and was maintained on the pre-test assessment. After

Table 2. Variations of GMFM-66

\begin{tabular}{ccccc} 
& baseline 1 & Pre-test & Post-test & baseline 2 \\
\hline Subject 1 & 82.99 & 82.99 & 86.52 & 86.52 \\
Subject 2 & 77.46 & 77.46 & 78.28 & 75.34 \\
\hline
\end{tabular}


Table 3. Variations of PBS

\begin{tabular}{ccccc} 
& baseline 1 & Pre-test & Post-test & baseline 2 \\
\hline Subject 1 & 47 & 47 & 53 & 50 \\
Subject 2 & 47 & 47 & 51 & 50 \\
\hline
\end{tabular}

Table 4. Variations of one leg standing

(unit: second)

\begin{tabular}{cccc} 
& Baseline A & Intervention B & Baseline A' \\
\hline Subject 1 & $1.83 \pm 0.35$ & $2.49 \pm 0.15$ & $2.62 \pm 0.08$ \\
Subject 2 & $1.69 \pm 0.25$ & $2.43 \pm 0.22$ & $2.57 \pm 0.06$ \\
\hline
\end{tabular}

Table 5. Variations of symmetry index

\begin{tabular}{ccccc} 
& baseline 1 & Pre-test & Post-test & baseline 2 \\
Subject 1 & 81.3 & 83 & 86.9 & 89.5 \\
Subject 2 & 92.7 & 94 & 98.5 & 99.3 \\
\hline
\end{tabular}

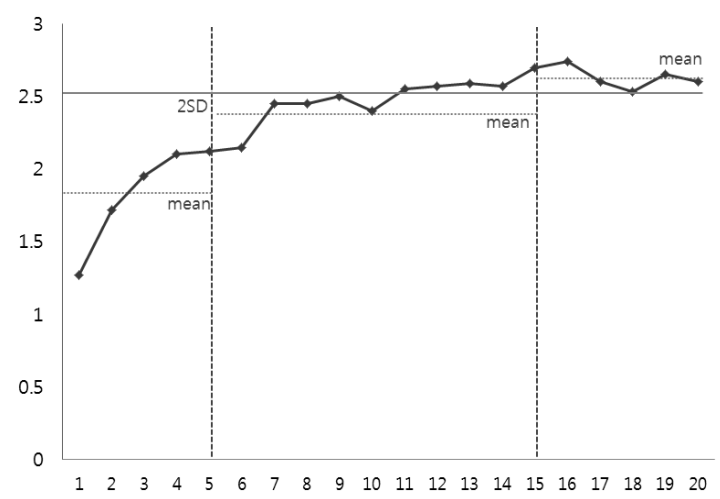

$\mathrm{M} \pm \mathrm{SD}$ : mean \pm standard deviation

Figure 3. Change of one leg standing in session(subject 1

intervention, the score improved to 51 , but, after the post-test, decreased to 50 .

The baseline one-leg-standing time of subject 1 was $1.83 \pm 0.35 \mathrm{~s}$, and that after intervention B $2.49 \pm$ $0.15 \mathrm{~s}$; the later phase A' score increased to $2.62 \pm$ 0.08 s. During intervention, the scores on 5 of 10 sessions exceeded the baseline mean \pm two standard deviation. The baseline one-leg-standing time of subject 2 was $1.69 \pm 0.25 \mathrm{~s}$, which rose to $2.43 \pm 0.22 \mathrm{~s}$ during intervention, and then to $2.57 \pm 0.06 \mathrm{~s}$ during follow-up. During intervention, the scores of 8 of 10 sessions exceeded the baseline value \pm two standard deviations.

\section{Gait}

The symmetry index of subject 1 increased from $83 \%$ prior to whole-body vibration to $86.9 \%$ after intervention and to $89.5 \%$ after the post-test. The symmetry index of subject 2 increased from $94 \%$ before intervention to $98.5 \%$ after intervention and $99.3 \%$ after the post-test.

\section{Discussion}

Whole-body vibration exercises have been used to treat various diseases and have been effective in children with cerebral palsy. ${ }^{15), 30) .31), 32)}$ Here, we inves- 
tigated the effect of such exercises on the gross motor function, balance, and gait of two children with cerebral palsy. A gross motor function measure (GMFM) is often used to assess functional activity in such children. ${ }^{15,31), 33), 34)}$ Ibrahim et al. (2014) reported significant improvements in the GMFM D and E domains of a whole-body vibration group (both $\mathrm{p}<0.05$ ). Our results suggest that such exercise may improve sensory function and exercise performance. We used the GMFM-66 to assess motor function. For subject 1, the score of $82.99 \%$ pre- test improved to $86.52 \%$ after intervention and was maintained after the post-test. Thus, whole-body vibration transmitted through the feet when standing may stimulate the senses and induce muscle contractions, improving and maintaining function. ${ }^{14)}$ For subject 2, the score of $77.46 \%$ pre-test increased slightly to $78.28 \%$ after intervention, but then decreased to $75.34 \%$ after the post-test. In relation to the foregoing Cheng (2015) showed that the duration of any effect was as short as 3 days, and the systematic review of Novak (2013) revealed a universal therapeutic effect for children with cerebral palsy, although analysis was difficult. ${ }^{35)}$ In addition, the feelings and general condition of children during assessment may compromise cooperation.

Children with cerebral palsy lack stability and balance because of muscle weakness, abnormal muscle tension, and difficulties in exercising. ${ }^{36)}$ Kown et al. (2011) reported that the equilibrium of such children was 41.7 PBS points prior to horse-riding but 45.8 points after riding $(\mathrm{p}=0.004){ }^{37)}$ Ahlborg et al. (2006) found that 8 weeks of whole-body vibration training for children with cerebral palsy significantly improved both dynamic balance and vestibular function. ${ }^{13)}$ Here, we assessed balance using the one- way PBS. In subject 1, 6 points of improvement were evident after intervention, but balance decreased after the post-test. In subject 2, an improvement of 4 points was evident after intervention, but, again, a decrease was apparent after the post-test. During intervention, the PBS scores increased, attributable to symmetrical weight support via uniform crossover vibration, and improvements in lower-limb sensation and strength. However, the score reductions evident after the post-test suggest that any effect of stimulation may be short term. ${ }^{38,39)}$ In particular, there has been a report that difficulty may arise due to the low degree of control ankle joint contributing to balance ability. ${ }^{40), 411}$

One leg standing improved after 5 of 10 sessions for subject 1 , and after 8 of 10 sessions for subject 2 . Liao et al. (2001) suggested that one-step tests usefully evaluated and predicted postural stability. ${ }^{42}$ Whole-body vibration improved adjustments in various directions, and postural stability (especially when moving). The walking ability of children with cerebral palsy is the area most in need of attention. Lee \& Chon (2013) reported significant improvement in walking speed, walking cycle, and ankle angle when whole-body vibration was used to improve the ability to control the lower extremities. ${ }^{30)}$ Here, we evaluated left-/right-side differences using a symmetry index to quantify the extent to which the curves of the two sides were similar; leg accelerations during gait were represented as curves. The pre-test score of subject 1 was $83 \%$, which became $86.9 \%$ after intervention and $89.5 \%$ after the post-test. For subject 2, the figures were 94\%, 98.5\%, and 99.3\%; little difference was evident between the right and left sides. Body-weight shifting and the ability to symmetrically support weight by the anterior and posterior lower limb regions directly affect functional gait and improve after whole-body vibrational training. ${ }^{15), 31)}$ We also found that pre-postural training induced active weight- shifting and improved postural control and walking ability. In addition, muscle weakness may limit anti-gravity motion and activity, ${ }^{43)}$ but whole-body vibration exercise may help improve function.

The limitations of our study include the fact that it is difficult to generalize our results because of the small numbers of participants and interventions and absence of control group; it was also difficult to control for variables that might affect our results. In addition, subject enthusiasm (in terms of participation), concentration, and emotional and physical commitments were all poor. 


\section{Conclusion}

We explored the effects of whole-body vibration on the gross motor function, balance, and gait of two children with cerebral palsy (thus exhibiting hemiplegia and bilateral paralysis) using an ABA study design. The initial score of subject 1 was $82.99 \%$, which improved to $86.52 \%$ after intervention, and then remained unchanged. The initial score of subject 2 was $77.46 \%$, which increased to $78.82 \%$ after intervention, but then decreased after the post-test. The initial PBS score of subject 1 was 47 and improved to 53 after intervention, but then decreased to 50. The initial PBS score of subject 2 was 47 and improved to 51 after intervention, but then decreased to 50 after the post-test. In the one-leg-standing test, the baseline A value was $1.83 \pm 0.35 \mathrm{~s}$, and the intervention $\mathrm{B}$ value $2.49 \pm 0.15 \mathrm{~s}$. The later phase $\mathrm{A}^{\prime}$ increased to 2.62 $\pm 0.08 \mathrm{~s}$. In addition, during intervention, the scores of 5 of 10 sessions exceeded the mean \pm two standard deviations of the baseline value. The baseline A one-leg-stand time was $1.69 \pm 0.25 \mathrm{~s}$, the interventional value $2.43 \pm 0.22 \mathrm{~s}$, and the post-test value 2.57 $\pm 0.06 \mathrm{~s}$ (thus slightly greater). During intervention, the scores of 8 out of 10 intervention sessions exceeded the baseline value \pm two standard deviations. For subject 1, gait symmetry index increased from $83 \%$ prior to intervention to $86.9 \%$ after intervention and $89.5 \%$ after the post-test; the figures for subject 2 were 94, 98.5, and 99.3\%, respectively. Our work suggests that long-term interventional studies with many more subjects are needed.

\section{References}

1. Yin Foo R, Guppy M, Johnston LM. Intelligence assessments for children with cerebral palsy: A systematic review. Developmental Medicine \& Child Neurology. 2013;55:811-818.

2. Rosenbaum P, Paneth N, Leviton A, et al. A report: The definition and classification of cerebral palsy April 2006. Dvelopmental Medicine \& Child Neurology. 2007;109, 8-14.

3. Ruck J, Chabot G, Rauch, F. Vibration treatment in cerebral palsy: A randomized controlled pilot study. The Journal of Musculoskeletal and Neuronal Interactions. 2010;10:77-83.

4. Krigger KW. Cerebral palsy: An overview. American Family Physician. 2006;73(1), 91-100.

5. Ross SM, MacDonald M, Bigouette JP. Effects of strength training on mobility in adults with cerebral palsy: a systematic review. Disability and health journal, 9(3), 2016;375-384.

6. Dallmeijer AJ, Rameckers EA, Houdijk H, et al. Isometric muscle strength and mobility capacity in children with cerebral palsy. Disability and rehabilitation. 2017;39(2), 135-142

7. van Vulpen LF, de Groot S, Rameckers E, et al. Improved Walking Capacity and Muscle Strength After Functional Power-Training in Young Children With Cerebral Palsy. Neurorehabilitation and neural repair. 2017;31(9), 827-841.

8. C. Stark, P. Herkenrath, H. Hollmann, et al. Early vibration assisted physiotherapy in toddlers with cerebral palsy - a randomized controlled pilot trial. J Musculoskelet Neuronal Interact. 2016;16(3):183-192

9. Damiano DL, Stanley CJ, Ohlrich L, et al. Task-specific and functional effects of speed-focused elliptical or motor-assisted cycle training in children with bilateral cerebral palsy: randomized clinical trial. Neurorehabilitation and neural repair. 2017;31(8),736-745.

10. Bania TA, Dodd KJ, Baker RJ, et al. The effects of progressive resistance training on daily physical activity in young people with cerebral palsy: a randomised controlled trial. Disability and rehabilitation. 2016;38(7), 620-626.

11. Ravi DK, Kumar N, Singhi P. Effectiveness of virtual reality rehabilitation for children and adolescents with cerebral palsy: an updated evidence-based systematic review. Physiotherapy. 2017;103(3), 245-258.

12. Franki I, Desloovere K, De Cat J, et al. The evidence-base for basic physical therapy techniques targeting lower limb function in children with cerebral palsy: a systematic review using the International Classification of Functioning, Disability and Health as a conceptual framework. J Rehabil Med. 2012; 44:385-95.

13. Ahlborg L, Andersson C, Julin P. Whole-body vibration training compared with resistance training: effect on spasticity, muscle strength and motor performance in 
adults with cerebral palsy. Journal of rehabilitation medicine,. 2006;38(5), 302-308.

14. El-Shamy SM. Effect of whole-body vibration on muscle strength and balance in diplegic cerebral palsy: a randomized controlled trial. American journal of physical medicine \& rehabilitation. 2014;93(2), 114-121.

15. Ko MS, Sim YJ, Kim DH, et al. Effects of three weeks of whole-body vibration training on joint-position sense, balance, and gait in children with cerebral palsy: A randomized controlled study. Physiotherapy Canada. 2016;68(2), 99-105.

16. Dickin DC, McClain MA, Hubble RP, et al. Changes in postural sway frequency and complexity in altered sensory environments following whole body vibrations. Human movement science. 2012;31(5), 1238-1246.

17. Saquetto M, Carvalho V, Silva C, et al. The effects of whole body vibration on mobility and balance in children with cerebral palsy: a systematic review with meta-analysis. J Musculoskelet Neuronal Interact .2015;15:137-144.

18. Cardinale M, Bosco C. The use of vibration as an exercise intervention. Exercise and sport sciences reviews. 2003;31(1), 3-7.

19. Alotaibi M, Long T, Kennedy, et al. The efficacy of GMFM-88 and GMFM-66 to detect changes in gross motor function in children with cerebral palsy $(\mathrm{CP})$ : A literature review. Disabil. Rehabil. 2014;36(8), 617-627.

20. Russell DJ, Avery LM, Rosenbaum PL. Improved scaling of the Gross Motor Function Measure for children with cerebral palsy: Evidence of reliability and validity. Phys Ther. 2000;80, 873-85.

21. Wei S, Su-Juan W, Yuan-Gui L, et al. Reliability and validity of the GMFM-66 in 0-to 3-year-old children with cerebral palsy. American journal of physical medicine \& rehabilitation. 2006;85(2), 141-147.

22. Franjoine MR, Gunther JS, Taylor MJ. Pediatric balance scale: a modified version of the berg balance scale for the school-age child with mild to moderate motor impairment. Pediatr Phys Ther. 2003;15:114-28.

23. Drusini AG, Eleazer GP, Caiazzo M, et al. One-leg standing balance and functional status in an elderly community-dwelling population in northeast Italy. Aging Clin Exp Res, 2002, 14: 42-46.

24. Shimada H, Uchiyama Y, Kakurai S. Specific effects of balance and gait exercises on physical function among the frail elderly. Clin Rehabil, 2003,17: 472-479.

25. Lim SY, Lee BJ, Lee WH. Receiver operating characteristic curve analysis of the timed up and go test as a predictive tool for fall risk in persons with stroke: a retrospective study. Physical Therapy Rehabilitation Science 2018;7:54-60

26. Yoon SK, Kang SH. Effects of inclined treadmill walking training with rhythmic auditory stimulation on balance and gait in stroke patients. Journal of physical therapy science. 2016;28(12), 3367-3370.

27. Pau M, Leban B, Collu G, et al. Effect of light and vigorous physical activity on balance and gait of older adults. Archives of gerontology and geriatrics. 2014;59(3), 568-573.

28. Nourbakhsh MR, Ottenbacher KJ. The statistical analysis of single-subject data: a comparative examination.Physicaltherapy. 1994;74(8),768-776.

29. Gottman JM, Leiblum SR. How to do psychotherapy and how to evaluate it: A manual for beginners. Holt,Rinehart \& Winston. 1974.

30. Lee B, Chon S. Effect of whole body vibration training on mobility in children with cerebral palsy: a randomized controlled experimenter-blinded study. Clin Rehab. 2013;27(7):599-607.

31. Ibrahim MM, Eid MA, Moawd SA. Effect of whole-body vibration on muscle strength, spasticity, and motor performance in spastic diplegic cerebral palsy children. Egyptian Journal of Medical Human Genetics. 2014;15(2),173-179.

32. Cheng HYK, Ju YY, Chen CL, et al. Effects of whole body vibration on spasticity and lower extremity function in children with cerebral palsy. Human movement science. 2015;39, 65-72

33. Brien M, Sveistrup $H$. An intensive virtual reality program improves functional balance and mobility of adolescents with cerebral palsy. Pediatr Phys Ther 2011; 23: 258-66.

34. Dodd KJ, Taylor NF, Graham HK. A randomized clinical trial of strength training in young people with cerebral palsy. Developmental medicine and child neurology. 2003;45(10), 652-657.

35. Novak I, Mcintyre S, Morgan C, et al. A systematic review of interventions for children with cerebral palsy: state of the evidence. Developmental Medicine \& Child Neurology. 2013;55(10),885-910. 
36. Shumway-Cook A, Woollacott MH. Normal Postural Control. In: Motor Control: Translating Research Into Clinical Practice, 4th edn. Baltimore, MD: Lippincott Williams \& Wilkins, 2012: 161-94.

37. Kwon JY, Chang HJ, Lee JY, et al. Effects of hippotherapy on gait parameters in children with bilateral spastic cerebral palsy. Arch Phys Med Rehab 2011; 92: 774-9.

38. Broekmans T, Roelants M, Alders G, et al. Exploring the effects of a 20-week whole-body vibration training programme on leg muscle performance and function in persons with multiple sclerosis. Journal of Rehabilitation Medicine. 2010;42(9), 866-872.

39. Ruck J, Chabot G, Rauch F. Vibration treatment in cerebral palsy: A randomized controlled pilot study. J Musculoskelet Neuronal Interact. 2010;10(1), 77-83.

40. Pozo-Cruz BD, Adsuar JC, Parraca JA, et al. Using whole-body vibration training in patients affected with common neurological diseases: a systematic literature review. The of Alternative and Complementary Medicine. 2012;18(1),29-41.
41. Jeon SJ, Hwang BY, Lee KB, et al. Comparison of Foot Pressure Distribution and Balance Between Children with Cerebral Palsy and Normal Children. J Korean Soc Neur Ther.2015;19(3):1-7.

42. Liao HF, Mao PJ, Hwang AW. Test-retest reliability of balance tests in children with cerebral palsy. Developmental medicine and child neurology. 2001;43(3), 180-186.

43. Lee EJ. The Effects of Sling Exercise Based with Bobath Concept on the Balance of Spastic Diplegia Cerebral Palsy: Case Report. J Korean Soc Neur Ther.2018;22(3):11-18. 